\title{
Laparoscopic versus open radical antegrade modular pancreatosplenectomy for pancreatic cancer: a single-institution comparative study
}

\author{
Jing Huang ${ }^{1,2} \wedge$, Chaojie Xiong ${ }^{2}$, Ye Sheng ${ }^{2}$, Xinhua Zhou ${ }^{2}$, Cai-De Lu ${ }^{2}$, Xiujun Cai ${ }^{1}$ \\ ${ }^{1}$ Department of General Surgery, Sir Run Run Shaw Hospital, Zhejiang University School of Medicine, Hangzhou, China; ${ }^{2}$ Department of \\ Hepatobiliary and Pancreatic Surgery, Ningbo Medical Center Lihuili Hospital, Ningbo University, Ningbo, China \\ Contributions: (I) Conception and design: X Cai, J Huang; (II) Administrative support: X Cai; (III) Provision of study materials or patients: C Xiong; \\ (IV) Collection and assembly of data: J Huang, Y Sheng, X Zhou, CD Lu; (V) Data analysis and interpretation: J Huang; (VI) Manuscript writing: All \\ authors; (VII) Final approval of manuscript: All authors. \\ Correspondence to: Xiujun Cai, MD, PhD. Department of General Surgery, Sir Run Run Shaw Hospital, Zhejiang University School of Medicine, \\ Hangzhou 310009, China. Email: srrsh_cxj@zju.edu.cn.
}

Background Laparoscopic distal pancreatosplenectomy is an effective and safe surgical modality for
treating benign and borderline distal pancreatic tumors, but rarely for pancreatic cancer. This study aimed to
compare the feasibility and safety of laparoscopic and open radical antegrade modular pancreatosplenectomy
for pancreatic cancer.

Methods: Fifty-one patients with pancreatic cancer who underwent radical antegrade modular pancreatosplenectomy at Ningbo Medical Center Lihuili Hospital between January 2014 and July 2018 were enrolled. 20 patients underwent laparoscopic radical antegrade modular pancreatosplenectomy and 31 patients received open radical antegrade modular pancreatosplenectomy. Postoperative and short-term outcomes of the two groups of patients were analyzed.

Results: The mean operation time, length of postoperative hospital stay, and overall postoperative morbidity were similar in the two groups $(\mathrm{P}>0.05)$. The laparoscopic radical antegrade modular pancreatosplenectomy group lost less blood $(252.5 \pm 198.3$ vs. $472.6 \pm 428.0 \mathrm{~mL}, \mathrm{P}=0.037)$ and had lower transfusion rates $(10.0 \%$ vs. $35.4 \%, \mathrm{P}=0.041)$ than the open radical antegrade modular pancreatosplenectomy group. The laparoscopic group also had statistically significantly earlier passing of first flatus $(2.5 \pm 0.8 \mathrm{vs}$. $3.2 \pm 1.2$ days, $\mathrm{P}=0.028)$ and first oral intake $(2.9 \pm 1.0$ vs. $3.7 \pm 1.6$ days, $\mathrm{P}=0.042)$. Furthermore, the rates of postoperative pancreatic fistula $(45.0 \%$ vs. $32.3 \%)$ and overall complications $(70.0 \%$ vs. $74.2 \%)$ were not statistically difference between the two groups. The survival rates at 6 months, 1 year, and 2 years after surgery were not statistically difference between the laparoscopic and open groups $(94.4 \%$ vs. $93.5,67.0 \%$ vs. $78.0 \%$, and $50.2 \%$ vs. $38.3 \%$, respectively).

Conclusions: The results of this study show that laparoscopic radical antegrade modular pancreatosplenectomy is feasible and safe for the treatment of pancreatic cancer.

Keywords: Pancreatic cancer; laparoscopic surgery; open surgery; radical antegrade modular pancreatosplenectomy

Submitted Dec 18, 2020. Accepted for publication Mar 18, 2021.

doi: $10.21037 / g s-21-56$

View this article at: http://dx.doi.org/10.21037/gs-21-56

$\wedge$ ORCID: 0000-0003-3245-3605. 


\section{Introduction}

With the continuous development of laparoscopic technology in recent years, laparoscopic surgery has increasingly been applied in the diagnosis and treatment of variety diseases. Laparoscopic distal pancreatectomy is confirmed as being a safe approach to treating benign and borderline tumors of the pancreatic body and tail. Furthermore, involving less postsurgical pain and shorter length of hospital stay for patients (1), the procedure has gradually become a standard surgical treatment (2). Studies have evidenced that laparoscopic distal pancreatectomy is as safe and effective as open surgery in the treatment of pancreatic body and tail cancer (3-10). Nevertheless, the use of this approach is still controversial due to the positioning of the pancreas deep in the retroperitoneal space and the associated difficulty in achieving negative pancreatic margins and effective lymph node dissection $(11,12)$. Radical antegrade modular pancreatosplenectomy (RAMPS), which was originally reported by Strasberg in 2003, has been developed based on N1 lymph node dissection using the modular setting of the posterior plane of dissection to obtain negative posterior margins (13). However, there have been few studies comparing the clinical outcomes of laparoscopic surgery and laparotomy with RAMPS procedure in the treatments of pancreatic body and tail cancer. In the current study, we compared the clinical data of 20 patients who underwent laparoscopic RAMPS (LRAMPS) and 31 patients who received open RAMPS (ORAMPS) for pancreatic cancer, in an effort to determine the safety and feasibility of laparoscopic radical antegrade modular pancreatosplenectomy surgery for treating this malignancy and to provide reference for its clinical application.

We present the following article in accordance with the STROBE reporting checklist (available at http://dx.doi. org/10.21037/gs-21-56).

\section{Methods}

\section{General patient data}

Patients $(\mathrm{n}=51)$ who underwent radical antegrade modular pancreatosplenectomy surgery in Ningbo Medical Center Lihuili Hospital between January 2014 and July 2018 were selected. The inclusion criteria for patients were as follows: (I) tumor located in the pancreatic body or tail; (II) pancreatic cancer confirmed by postoperative pathological examination; (III) no distant metastasis was found during
Table 1 Preoperative features comparison of patients undergoing LRAMPS and ORAMPS

\begin{tabular}{lccc}
\hline Group & $\begin{array}{c}\text { LRAMPS } \\
(\mathrm{n}=20)\end{array}$ & $\begin{array}{c}\text { ORAMPS } \\
(\mathrm{n}=31)\end{array}$ & P value \\
\hline Age (years, mean $\pm \mathrm{SD})$ & $67.2 \pm 8.4$ & $66.9 \pm 9.1$ & 0.917 \\
BMl $\left(\mathrm{kg} / \mathrm{m}^{2}\right.$, mean $\left.\pm \mathrm{SD}\right)$ & $23.4 \pm 2.5$ & $22.5 \pm 2.0$ & 0.267 \\
Sex & & & 0.91 \\
Female & 10 & 16 & \\
Male & 10 & 15 & \\
ASA classification score & & & 0.803 \\
1 & 11 & 15 & \\
2 & 8 & 15 & \\
3 & 1 & 1 & \\
\hline
\end{tabular}

SD, standard deviation; BMI, body mass index; ASA classification, American Society of Anesthesiologists physical status classification; LRAMPS, laparoscopic radical antegrade modular pancreatosplenectomy; ORAMPS, open radical antegrade modular pancreatosplenectomy.

the preoperative or intraoperative period. (IV) tumor located at least 1-2 $\mathrm{cm}$ away from the celiac axis and superior mesenteric artery (SMA) or vein. The exclusion criteria for patients were as follows: (I) distant tumor metastasis were detected by the preoperative imaging; (II) postoperative routine pathology results showed a benign or borderline tumor; (III) cases in which a safety margin were difficult to be achieved while sparing the major vessel, such as the superior mesenteric artery (SMA) or vein, were excluded from the study. The study was approved by the ethics committee of the Lihuili Hospital (IRB No. KY2021SL006-02). Patients provided written informed consent from each participant, and the procedures were in compliance with Helsinki Declaration (as revised in 2013).

The patients were divided into the laparoscopic group (LRAMPS group, $\mathrm{n}=20$ ) and the open group (ORAMPS group, $n=31$ ) according to the surgical procedure they received. The LRAMPS group included 10 males and 10 females aged $67.2 \pm 8.4$ years old with a preoperative body mass index (BMI) of $23.4 \pm 2.5 \mathrm{~kg} / \mathrm{m}^{2}$. In the ORAMPS group were 16 males and 15 females aged $66.9 \pm 9.1$ years old with a preoperative BMI of $22.5 \pm 2.0 \mathrm{~kg} / \mathrm{m}^{2}$. There was no significant difference in the preoperative general characteristics between the two groups (Table 1). Postoperative pathological diagnosis showed pancreatic ductal adenocarcinoma in all patients in the LRAMPS group and 28 patients in the ORAMPS group. 
Table 2 Comparison of intraoperative and postoperative information of patients in the LRAMPS and ORAMPS groups

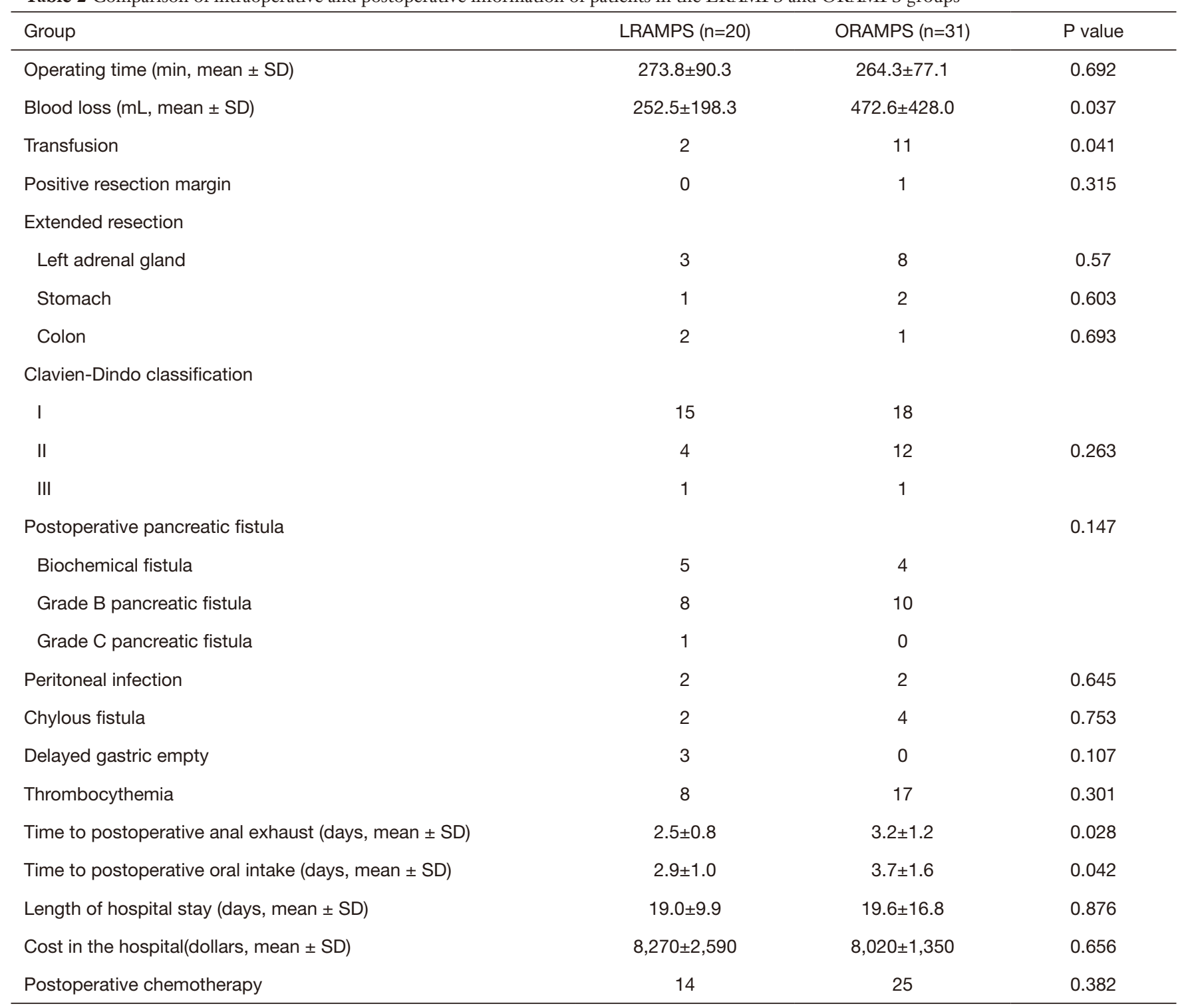

SD, standard deviation; LRAMPS, laparoscopic radical antegrade modular pancreatosplenectomy; ORAMPS, open radical antegrade modular pancreatosplenectomy.

Among the 3 other patients in the ORAMPS group, there were 2 cases of intraductal papillary mucinous tumor-related invasive carcinoma and 1 case of adenosquamous carcinoma (Table 2).

\section{Operative technique}

\section{Laparoscopic surgery}

The patients were placed in the supine position. The surgeon was positioned to the right side of the patient and used the five holes method. The observation hole was made by puncturing the lower umbilical edge with a $10-\mathrm{mm}$ trocar, and an artificial pneumoperitoneum was established to maintain the abdominal pressure at $12 \mathrm{mmHg}$. All the puncture holes were basically distributed in an inverted triangle (Figure 1). Laparoscopic and open RAMPS were performed using the same fundamental surgical procedure. The pancreatic segments were exposed through transection of the gastrocolic ligament with a harmonic scalpel, which allowed the tumor location and size to be clearly defined. 

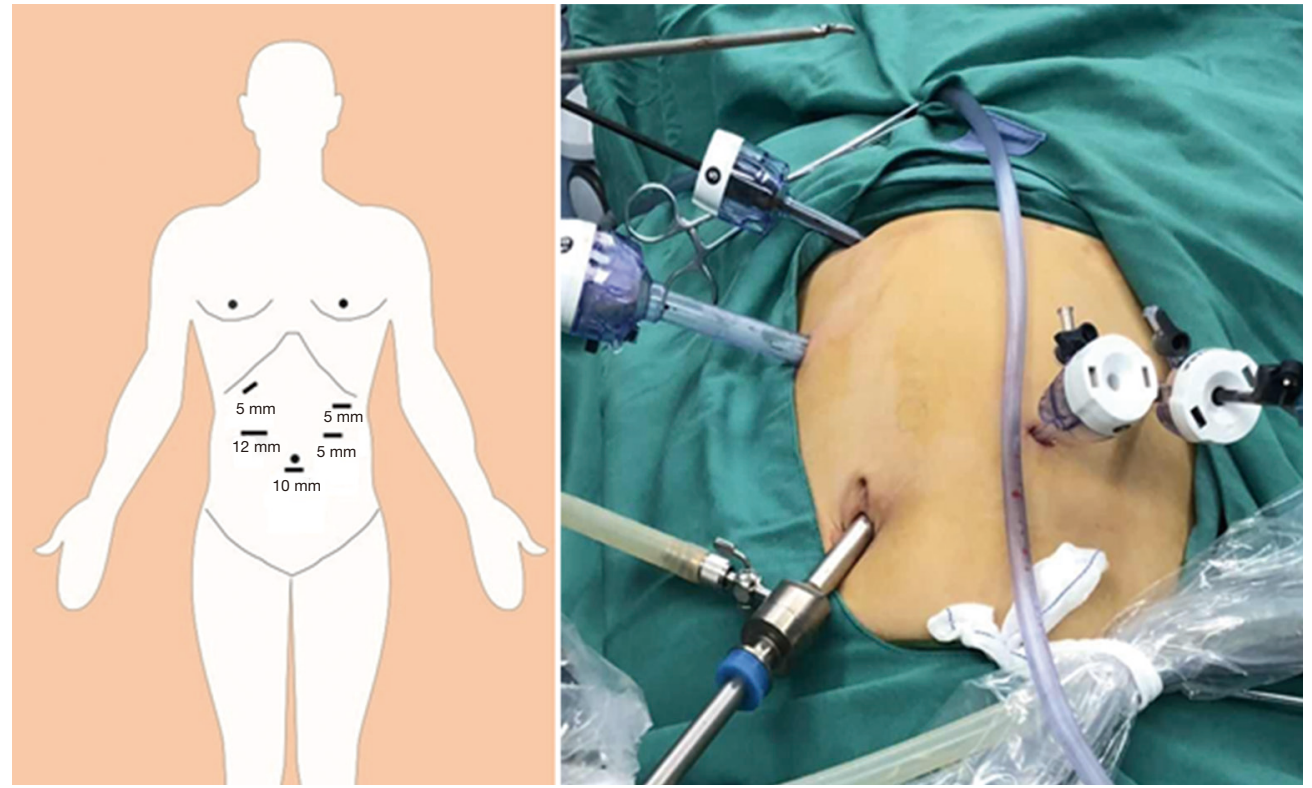

Figure 1 Trocar placement for laparoscopic radical antegrade modular pancreatosplenectomy.

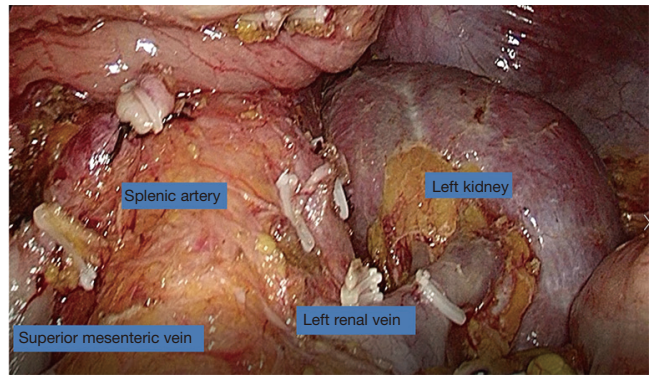

Figure 2 View of the laparoscopic radical antegrade modular pancreatosplenectomy after the completion of the resection stage.

After careful dissection of the pancreatic neck a complete window could be made via a vascular plane between the pancreatic neck and the superior mesenteric vein (SMV). Then, the superior and inferior borders of the pancreas were separated to expose the splenic arteries and veins, which were dissected and ligated. The dissection of lymph nodes around the common hepatic artery was performed. The division of the neck of the pancreas was performed by a laparoscopic Endo-GIA stapler (ENDO GIA universal STRAIGHT 60 3.5, Covidien). The pancreas was dissected at a distance of $1-2 \mathrm{~cm}$ from the tumor. If necessary, the left gastric artery was slung and lifted to remove the surrounding lymph nodes. Dissection was subsequently performed in a right-to-left fashion including the soft tissue around the celiac trunk and the splenic vessels, with an intact fascial layer covering the adrenal gland and perinephric soft tissue. For the requirement of tumor radical resection, some patients underwent extended resections, which involved the left adrenal gland resection, and partial resection of the stomach or the transverse colon (Figure 2).

\section{Open surgery}

The procedure for open surgery was similar to that of laparoscopic surgery except that the pancreas was dissected using a scalpel after the suspension of the pancreatic neck with a suspension sling. The pancreatic duct was then ligated, and the pancreatic section was continuously sutured by 4-0 Prolene thread (Figures 3,4).

\section{Postoperative management}

Postoperatively, a peritoneal drainage tube was routinely placed in the operative area, and the drainage fluid and hemodiastase on day 3 after surgery were detected. Patients were given fluid intake after their first anal exhaust after surgery. When the amount of peritoneal drainage fluid fell below $10 \mathrm{~mL} / 24$ hours, the peritoneal drainage tube was removed. Pancreatic fistula was assessed according to the latest standards issued by The International Study Group on Pancreatic Fistula (ISGPF) (13), and postoperative complications were assessed according to the Clavien- 

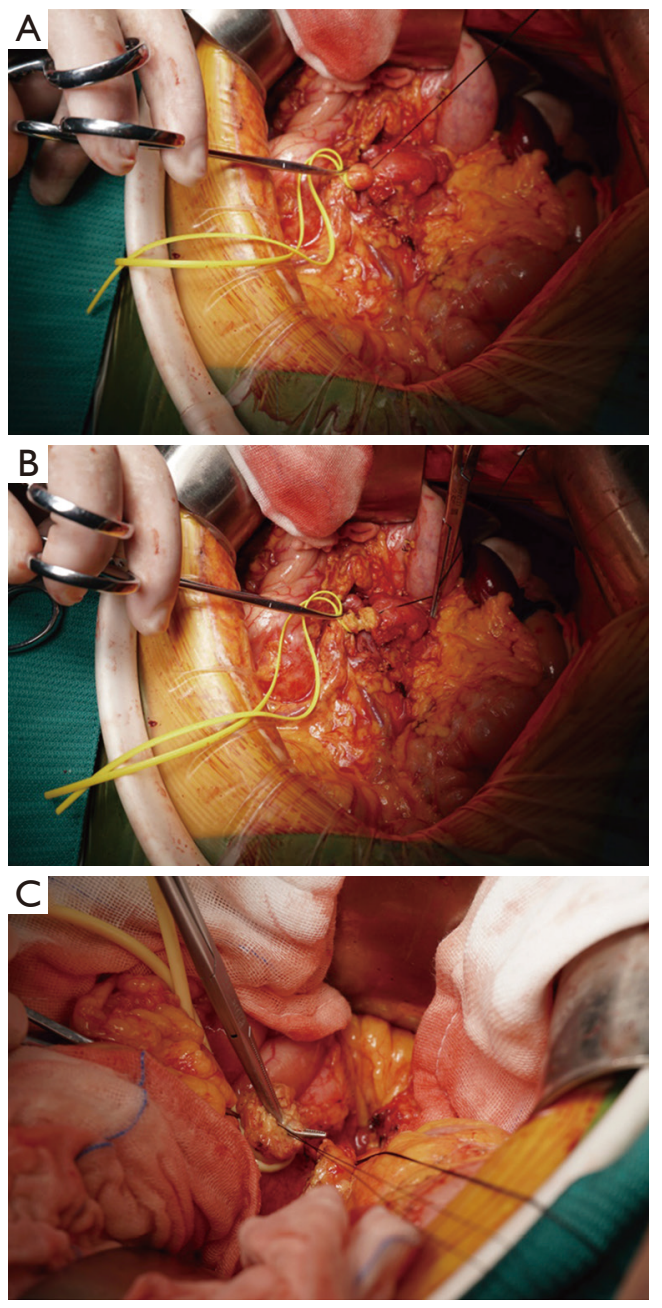

Figure 3 Management of pancreatic section during open approach. (A) The neck of the pancreas was suspended with a suspension sling; (B) the pancreatic neck is dissected using a scalpel; (C) the pancreatic duct was ligated and the section was continuously sutured with 4-0 Prolene thread.

Dindo classification (14).

\section{Statistical analysis}

The statistical software SPSS 19.0 (SPSS Inc., Chicago, IL) was used to analyze the data. All measurement data were expressed as the mean \pm standard deviation (SD). The $t$-test was applied to compare means between the two groups. The Chi squared test or Fisher's exact probability test was used for enumeration data, and the rank-sum test was used for ranked data. Survival rates were analyzed using the log-rank method, and the Kaplan-Meier method was used to analyze

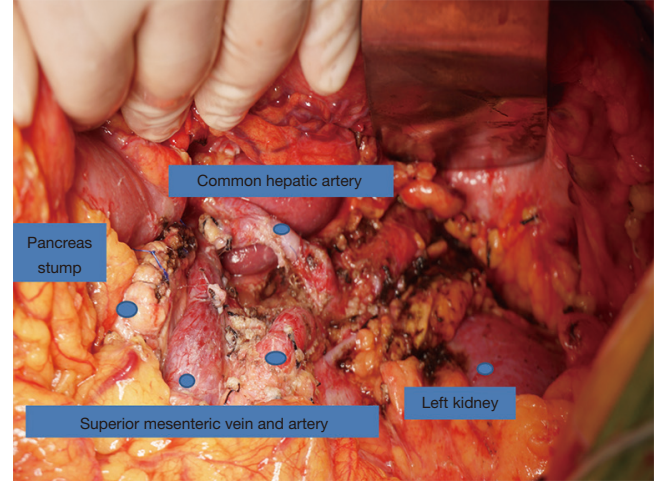

Figure 4 View of the open posterior radical antegrade modular pancreatosplenectomy after the completion of the resection stage.

postoperative survival time. The criterion for statistical significance was set as $\mathrm{P}<0.05$.

\section{Results}

\section{Intraoperative conditions}

The LRAMPS group lost less blood $(252.5 \pm 198.3$ vs. $472.6 \pm 428.0 \mathrm{~mL})$ and had a lower transfusion rate $(10.0 \%$ vs. $35.4 \%$ ) than the ORAMPS group, and the differences were statistically significant $(\mathrm{P}<0.05)$. There were no statistically significant differences in the operative time, extended excision rate, or the rate of positive margins between the two groups $(\mathrm{P}>0.05)$.

\section{Postoperative pathology}

The amount of lymph nodes removed was $9.6 \pm 6.4$ in the LRAMPS group, compared with $12.8 \pm 5.8$ in the ORMPS group. The tumor size was $4.2 \pm 1.9$ and $4.2 \pm 1.6 \mathrm{~cm}$ in the LRAMPS and ORAMPS groups, respectively, and poorly differentiated carcinoma accounted for $55.0 \%$ and $67.7 \%$ of cases in the two groups, respectively. There was no statistically significant difference between two groups (Table 2).

\section{Perioperative complications and postoperative recovery}

The first postoperative flatus and first oral intake occurred statistically significantly earlier in the LRAMPS group than in the ORAMPS group $(\mathrm{P}<0.05)$. However, no statistically significantly differences were observed between the two groups in terms of Clavien-Dindo classification, length of hospital stay, the incidence of pancreatic fistula, peritoneal 
Table 3 Comparison of pathological data of the LRAMPS and ORAMPS groups

\begin{tabular}{|c|c|c|c|}
\hline Group & $\begin{array}{l}\text { LRAMPS } \\
(n=20)\end{array}$ & $\begin{array}{c}\text { ORAMPS } \\
(n=31)\end{array}$ & $P$ value \\
\hline Tumor size (cm) & $4.2 \pm 1.9$ & $4.2 \pm 1.6$ & 0.927 \\
\hline Differentiated degree & & & 0.362 \\
\hline Well & 1 & 1 & \\
\hline Moderate & 8 & 9 & \\
\hline Poor & 11 & 21 & \\
\hline Tumor stage & & & 0.888 \\
\hline $\mathrm{T} 1$ & 2 & 5 & \\
\hline $\mathrm{T} 2$ & 8 & 9 & \\
\hline T3 & 8 & 15 & \\
\hline $\mathrm{T} 4$ & 2 & 2 & \\
\hline $\mathrm{N}$ stage & & & 0.446 \\
\hline No & 14 & 19 & \\
\hline $\mathrm{N} 1$ & 6 & 10 & \\
\hline $\mathrm{N} 2$ & 0 & 2 & \\
\hline TNM stage & & & 0.777 \\
\hline I & 7 & 9 & \\
\hline II & 9 & 16 & \\
\hline III & 4 & 6 & \\
\hline \multicolumn{4}{|l|}{ Lymph nodes } \\
\hline No. of nodes dissected & $9.6 \pm 6.4$ & $12.8 \pm 5.8$ & 0.203 \\
\hline No. of metastatic nodes & $0.7 \pm 1.0$ & $0.9 \pm 1.5$ & 0.554 \\
\hline
\end{tabular}

LRAMPS, laparoscopic radical antegrade modular pancreatosplenectomy; ORAMPS, open radical antegrade modular pancreatosplenectomy; TNM stage: American Joint Cancer Committee/Union International Cancer TNM staging system

infection, chylous leakage, or delayed gastric emptying. Among the complications recorded, the biochemical fistula occurred in 5 patients, the grade B pancreatic fistula occurred in 8 patients, and the grade $\mathrm{C}$ pancreatic fistula occurred in one patient in the LRAMPS group. In the ORAMPS group, the biochemical fistula and the grade B pancreatic fistula occurred in 4 and 10 patients, respectively, while no cases of the grade $\mathrm{C}$ pancreatic fistula were observed. According to the definition of pancreatic fistula in the latest guidelines, pancreatic fistula was not included biochemical fistula (Table 3). Therefore, the incident of pancreatic fistula was $45 \%$ and $32.3 \%$ for the LRAMPS group and the ORAMPS group, respectively. Patients who experienced postoperative pancreatic fistula were treated with postoperative drainage, enzyme inhibitors, fasting, and parenteral nutrition support. For patients with obstructed drainage, puncture and drainage or negative pressure irrigation and drainage were performed under the guidance of B-ultrasound. All of the patients were recovered after symptomatic therapy, except one patient in the LRAMPS group required reoperation for the pancreatic fistula and peritoneal infection and recovered. There were no postoperative mortalities.

\section{Long-term follow-up}

The follow-up cut-off date for all patients was in July 2018, and the follow-up period ranged from 1-24 months. The median follow-up time in the LRAMPS group was 15 months, compared with 23 months in the ORAMPS group. The 6-month, 1-year, and 2-year survival rates were no statistically significantly difference between the two groups (94.4\% vs. $93.5 \%$; $67.0 \%$ vs. $78.0 \%$, and $50.2 \%$ vs. $38.3 \%$, respectively), as analyzed using the log-rank method. The Kaplan-Meier survival curves showed no statistically significant difference in postoperative survival time between the groups $(\mathrm{P}=0.411)$ (Figure 5).

\section{Discussion}

Pancreatic cancer is one of the most common malignancies of the digestive system. Because pancreatic cancer is not sensitive to chemoradiotherapy, surgical resection is the only radical treatment option. For cancer in the pancreatic body and tail, the radical surgery is closely related to the negative resection margin and the dissection of lymph nodes (11). In 2003, Strasberg described an approach to resect left-sided pancreatic cancer called radical antegrade modular pancreatosplenectomy (RAMPS), which is a novel procedure that includes a horizontal dissection plane from right-to-left and radical resection of regional lymph nodes based on anatomic drainage of the pancreas (13). However, laparoscopic surgery with RAMPS procedure is still challenging for surgeons. Few studies about the laparoscopic radical antegrade modular pancreatosplenectomy for pancreatic body and tail cancer have reported $(3-5,8)$, the application of laparoscopic RAMPS is still controversial due to oncological safety concerns regarding en bloc resection, negative margins, and complexity of the surgery. 


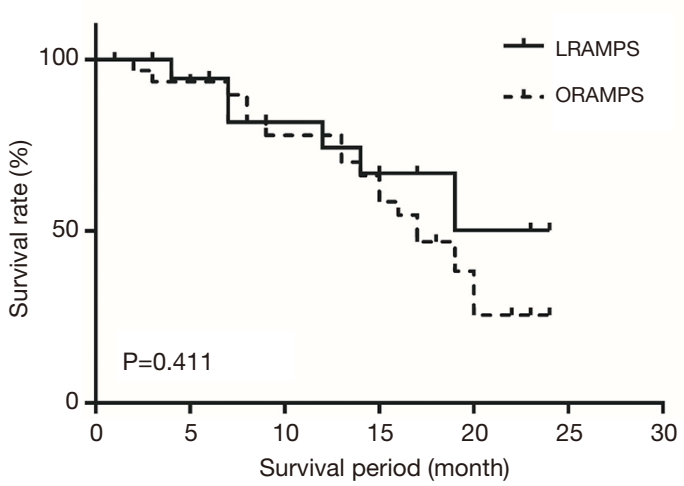

Figure 5 Comparison of the survival curves between the laparoscopic radical antegrade modular pancreatosplenectomy (LRAMPS) group ( $\mathrm{n}=20)$ and the open radical antegrade modular pancreatosplenectomy (ORAMPS) group $(n=31)$ of patients with pancreatic cancer $(\mathrm{P}=0.411)$.

Laparoscopic operation has been widely accepted due to its' minimally invasive approach and advantages, such as less bleeding, smaller transfusion volumes requirement, and shorter incisions with less pain. Consequently, these advantages also applied to laparoscopic RAMPS. At the beginning of the laparoscopic surgery, studies reported that its operation time was longer than open surgery due to the immature technique and medical equipment (15-17). Nevertheless, with its continuous development in recent decades, the advantages of laparoscopic surgery have become clearer. First, surgeons are able to dissect the tissue and vessels more elaborately under a laparoscope, thus reducing blood loss; moreover, due to the smaller incision, patients who undergo laparoscopic surgery recover faster after the operation. One meta-analysis of patients with pancreatic body and tail cancer demonstrated that the laparoscopic distal pancreatectomy group showed remarkably less blood loss and lower transfusion rates than the open distal pancreatectomy group, while the operating time showed no significance between the two groups (4). In our study, blood loss and the transfusion rate in the LRAMPS group were statistically significantly lower than those in the ORAMPS group, while no statistical difference was observed in the operating time, which is consistent with most reports.

As the main postoperative complication of the pancreatic surgery, pancreatic fistula has been repeated assessed. The latest staging criteria for pancreatic fistula defines grade A pancreatic fistula as being biochemical fistula, and it was therefore excluded from the incidence of postoperative pancreatic fistula in this study. According to the criteria, in the LRAMPS group, there were 9 cases of pancreatic fistula (45\%), of which 8 cases were grade B and one was grade C; in the ORAMPS group, there were 10 cases of pancreatic fistula, all of which were grade $B$. The incidence of pancreatic fistula between the two groups showed no significant difference $(\mathrm{P}>0.05)$. Both procedures for the surgical section of the pancreas had relatively high incidents of pancreatic fistula. Patients who experienced postoperative pancreatic fistula were treated with postoperative drainage, enzyme inhibitors, fasting, and parenteral nutrition support. For patients with obstructed drainage, puncture and drainage or negative pressure irrigation and drainage were performed under the guidance of B-ultrasound. The outcomes of our study showed that there were no statistically significant differences between the groups for other postoperative complications such as peritoneal infection, chylous fistula, delayed gastric emptying, thrombocythemia, and length of hospital stay. First flatus and first oral intake occurred significantly earlier in the LRAMPS group than in the ORAMPS group, indicating that the LRAMPS group required a shorter time to recover gastrointestinal function. There were no postoperative mortalities. Preliminary studies have shown laparoscopic radical antegrade modular pancreatosplenectomy to be as safe and reliable as open approach, while achieving faster postoperative recovery.

Laparoscopic surgery has been proven by accumulative studies to be a safe and effective treatment for tumors of the pancreatic body and tail. It has gradually become a standard surgical treatment benign and low-grade malignant pancreatic body and tail tumors. Nonetheless, laparoscopic surgery is immensely challenging and may increase the difficulty in obtaining negative pancreatic resection margins and lymph node clearance, thus affecting patient prognosis. However, recent studies showed that there was no difference in the positive rate of resection margins or in the number of lymph nodes dissected between laparoscopic surgery and open surgery, while the postoperative survival time was comparable (18-24). Some researchers have even reported that laparoscopic surgery is associated with the dissection of a higher number of lymph nodes (25). Our results were in accordance with those of the abovementioned studies that reported no statistically significant difference in the amount of lymph nodes during the two procedures (LRAMPS: $9.6 \pm 6.4$ and ORAMPS: $12.8 \pm 5.8$ ).

From the perspective of tumor resection margins, the 
postoperative pancreatic resection margin and the posterior peritoneal resection margin were used to determine the rate of positive margins (26). Both types of resection margins were negative in the LRAMPS group, while one case in the ORAMPS group was determined to have a positive resection margin which was followed further resection. However, there was no significant difference in the rate of positive surgical margins between the two groups. In the LRAMPS group, 6 patients received extended resection of other organs, including left adrenal gland $(\mathrm{n}=3)$, partial colon resection $(n=2)$, and partial stomach resections $(n=1)$. In the ORAMPS group, 11 patients underwent extended resection, including left adrenal gland $(\mathrm{n}=8)$, partial stomach $(\mathrm{n}=2)$, and partial colon resections $(n=1)$. However, if the adjacent organs were invaded by tumor, confirmed by preoperative imaging, it is strongly recommended the patient undergo open operation. In terms of tumor differentiation, $55 \%$ and $40 \%$ of the LRAMPS group had poorly and moderately differentiated cancers, respectively, compared to $67.7 \%$ and $29.0 \%$ of the ORAMPS group, respectively. Evidently, both groups possessed a high proportion of poorly differentiated cancers. There were no statistically significant difference between the postoperative survival times of patients in the two groups $(\mathrm{P}=0.261)$. These results suggest that for patients with pancreatic body and tail cancer with early TNM staging, the use of laparoscopic or open surgery had no significant difference on survival time, even if the degree of tumor differentiation was poor.

For the technology of the laparoscopic RAMPS, Surgeons with the experience of laparoscopic surgery can easily adapt to a RAMPS laparoscopic approach. Compared with open surgery, the magnified view is in laparoscopic procedure provided a more objective dissection plane. Due to the positioning of the body and tail of pancreas in the retroperitoneal space, the surgeon can be easier to dissect the tissue in this region by the laparoscopic approach than open approach, which may be result in achieving negative margins and en-block resection. We believe these RAMPS characteristics contributed to the safe and feasible outcomes in laparoscopic approach.

In addition, it is difficult to reach firm conclusions because of the small sample size in our study. Large sample comparative studies are needed, since there were no surgical approach dependent survival differences (laparoscopic approach $v s$. open).

\section{Conclusions}

In conclusion, LRAMPS is a safe and feasible treatment for patients diagnosed with early- to mid-stage pancreatic body and tail cancers, even for those with poor tumor differentiation. The benefits of LRAMPS over ORMPS can be clearly deduced from this comparison, with the former possessing the advantages of less intraoperative blood loss and faster postoperative recovery. Moreover, we found no difference in the rate of postoperative complications, the amount of harvested lymph nodes, or postoperative survival time between the two surgical treatments. Therefore, the application of the laparoscopic radical antegrade module pancreatosplenectomy is worthy of being promoted in the clinical setting.

\section{Acknowledgments}

We express our thanks to members of the Department of Hepatobiliary Pancreatic Surgery at Ningbo Medical Center Lihuili Hospital who gave their advice and support during this research.

Funding: This work was supported by the Scientific Innovation Team Project of Ningbo (2013B82010), Ningbo Health Branding Subject Fund (PPXK2018-03), and the Medical Science and Technology Project of Zhejiang (2019ZD074).

\section{Footnote}

Reporting Checklist: The authors have completed the STROBE reporting checklist. Available at http://dx.doi. org/10.21037/gs-21-56

Data Sharing Statement: Available at http://dx.doi. org/10.21037/gs-21-56

Conflicts of Interest: All authors have completed the ICMJE uniform disclosure form (available at http://dx.doi. org/10.21037/gs-21-56). The authors have no conflicts of interest to declare.

Ethical Statement: The authors are accountable for all aspects of the work in ensuring that questions related to the accuracy or integrity of any part of the work are 
appropriately investigated and resolved. All procedures performed in this study involving human participants were in accordance with the Declaration of Helsinki (as revised in 2013). The study was approved by the ethics committee of the Lihuili Hospital (IRB No. KY2021SL006-02) and informed consent was taken from all the patients.

Open Access Statement: This is an Open Access article distributed in accordance with the Creative Commons Attribution-NonCommercial-NoDerivs 4.0 International License (CC BY-NC-ND 4.0), which permits the noncommercial replication and distribution of the article with the strict proviso that no changes or edits are made and the original work is properly cited (including links to both the formal publication through the relevant DOI and the license). See: https://creativecommons.org/licenses/by-nc-nd/4.0/.

\section{References}

1. Mabrut JY, Fernandez-Cruz L, Azagra JS, et al. Laparoscopic pancreatic resection: results of a multicenter European study of 127 patients. Surgery 2005;137:597-605.

2. Mehrabi A, Hafezi M, Arvin J, et al. A systematic review and meta-analysis of laparoscopic versus open distal pancreatectomy for benign and malignant lesions of the pancreas: it's time to randomize. Surgery 2015;157:45-55.

3. Bauman MD, Becerra DG, Kilbane EM, et al. Laparoscopic distal pancreatectomy for pancreatic cancer is safe and effective. Surg Endosc 2018;32:53-61.

4. Gavriilidis P, Roberts KJ, Sutcliffe RP. Laparoscopic versus open distal pancreatectomy for pancreatic adenocarcinoma: a systematic review and meta-analysis. Acta Chir Belg 2018;118:278-86.

5. Kantor O, Bryan DS, Talamonti MS, et al. Laparoscopic Distal Pancreatectomy for Cancer Provides Oncologic Outcomes and Overall Survival Identical to Open Distal Pancreatectomy. J Gastrointest Surg 2017;21:1620-5.

6. Nakamura M, Wakabayashi G, Miyasaka Y, et al. Multicenter comparative study of laparoscopic and open distal pancreatectomy using propensity score-matching. J Hepatobiliary Pancreat Sci 2015;22:731-6.

7. Venkat R, Edil BH, Schulick RD, et al. Laparoscopic distal pancreatectomy is associated with significantly less overall morbidity compared to the open technique: a systematic review and meta-analysis. Ann Surg 2012;255:1048-59.

8. Raoof M, Ituarte PHG, Woo Y, et al. Propensity scorematched comparison of oncological outcomes between laparoscopic and open distal pancreatic resection. Br J
Surg 2018;105:578-86.

9. Stauffer JA, Rosales-Velderrain A, Goldberg RF, et al. Comparison of open with laparoscopic distal pancreatectomy: a single institution's transition over a 7-year period. HPB (Oxford) 2013;15:149-55.

10. Lee SY, Allen PJ, Sadot E, et al. Distal pancreatectomy: a single institution's experience in open, laparoscopic, and robotic approaches. J Am Coll Surg 2015;220:18-27.

11. Kooby DA, Chu CK. Laparoscopic management of pancreatic malignancies. Surg Clin North Am 2010;90:427-46.

12. Kang CM, Lee SH, Lee WJ. Minimally invasive radical pancreatectomy for left-sided pancreatic cancer: current status and future perspectives. World J Gastroenterol 2014;20:2343-51.

13. Strasberg SM, Drebin JA, Linehan D. Radical antegrade modular pancreatosplenectomy. Surgery 2003;133:521-7.

14. Bassi C, Marchegiani G, Dervenis C, et al. The 2016 update of the International Study Group (ISGPS) definition and grading of postoperative pancreatic fistula: 11 Years After. Surgery 2017;161:584-91.

15. Clavien PA, Barkun J, de Oliveira ML, et al. The ClavienDindo classification of surgical complications: five-year experience. Ann Surg 2009;250:187-96.

16. Casadei R, Ricci C, D'Ambra M, et al. Laparoscopic versus open distal pancreatectomy in pancreatic tumours: a casecontrol study. Updates Surg 2010;62:171-4.

17. Aly MY, Tsutsumi K, Nakamura M, et al. Comparative study of laparoscopic and open distal pancreatectomy. J Laparoendosc Adv Surg Tech A 2010;20:435-40.

18. Matsumoto T, Shibata K, Ohta M, et al. Laparoscopic distal pancreatectomy and open distal pancreatectomy: a nonrandomized comparative study. Surg Laparosc Endosc Percutan Tech 2008;18:340-3.

19. Rehman S, John SK, Lochan R, et al. Oncological feasibility of laparoscopic distal pancreatectomy for adenocarcinoma: a single-institution comparative study. World J Surg 2014;38:476-83.

20. Vijan SS, Ahmed KA, Harmsen WS, et al. Laparoscopic vs open distal pancreatectomy: a single-institution comparative study. Arch Surg 2010;145:616-21.

21. Zhang Y, Chen XM, Sun DL. Laparoscopic versus open distal pancreatectomy: a single-institution comparative study. World J Surg Oncol 2014;12:327.

22. Marangos IP, Buanes T, Rosok BI, et al. Laparoscopic resection of exocrine carcinoma in central and distal pancreas results in a high rate of radical resections and long postoperative survival. Surgery 2012;151:717-23. 
23. Magge D, Gooding W, Choudry H, et al. Comparative effectiveness of minimally invasive and open distal pancreatectomy for ductal adenocarcinoma. JAMA Surg 2013;148:525-31.

24. Kooby DA, Hawkins WG, Schmidt CM, et al. A multicenter analysis of distal pancreatectomy for adenocarcinoma: is laparoscopic resection appropriate? J Am Coll Surg 2010;210:779-85, 786-7.

Cite this article as: Huang J, Xiong C, Sheng Y, Zhou X, Lu CD, Cai X. Laparoscopic versus open radical antegrade modular pancreatosplenectomy for pancreatic cancer: a singleinstitution comparative study. Gland Surg 2021;10(3):10571066. doi: $10.21037 / \mathrm{gs}-21-56$
25. Jayaraman S, Gonen M, Brennan MF, et al. Laparoscopic distal pancreatectomy: evolution of a technique at a single institution. J Am Coll Surg 2010;211:503-9.

26. Stauffer JA, Coppola A, Mody K, et al. Laparoscopic Versus Open Distal Pancreatectomy for Pancreatic Adenocarcinoma. World J Surg 2016;40:1477-84.

(English Language Editor: J. Reynolds) 